\title{
Effect of Air Lead Pollution on Blood Bilirubin and Lactate Dehydrogenase Levels among Occupationally Exposed Workers in Main Sudanese Cities
}

\author{
Hythem S. A. Saeed ${ }^{1}$, Abdelmonem M. Abdellah ${ }^{2}$, Fatima A. B. Abdalla ${ }^{3}$, \\ Abdel Rouf A. Abbas ${ }^{4}$, Nafisa A. ELgazali ${ }^{5}$ and Fathia A. Adam ${ }^{6}$ \\ ${ }^{1}$ Dept. of Biochemistry, AL Yarmouk College, Khartoum, Sudan, ${ }^{2}$ Allahawi for Research Consultation (ARC), \\ Khartoum North, Sudan, ${ }^{3}$ Dept. of Biochemistry, Faculty of Medicine, Omdurman Islamic University, Sudan \\ ${ }^{4}$ Dept. of Biochemistry, Faculty of Science, Omdurman Islamic University, Sudan, ${ }^{5}$ Department of Chemistry, \\ Faculty of Science, Bisha University, Saudi Arabia, ${ }^{6}$ Dept. of Chemistry, Faculty of Science, Bisha University, \\ Saudi Arabia, respectively.
}

\begin{abstract}
Up-regulation of bilirubin and lactate dehydrogenase in blood serum due to lead poisoning has been correlated to many adverse health impacts. Traffic policemen and petrol station workers are more likely affected by air lead pollution. This study was conducted to determine blood lead, bilirubin and lactate dehydrogenase levels in traffic policemen and petrol station workers, beside determination of some medical complications due to lead toxicity. A total of 150 subjects were randomly selected from different cities of Sudan, in which 100 samples taken as exposed group and 50 as un-exposed (control). Blood lead concentration was determined by using atomic absorption spectrometer. Biochemical parameters were measured in serum using standard methods. Data was collected with the aid of writing a questionnaire. Mean blood lead concentration in exposed group was found to be $32.2 \mu \mathrm{g} / \mathrm{dl}$, whereas in control was $12.4 \mu \mathrm{g} / \mathrm{dl}$. No correlation was found between blood lead levels and work duration in both exposed and control groups understudy. Serum lactate dehydrogenase $(L D H)$ was significantly higher $(p<0.001)$ in exposed group than in control. The Serum total bilirubin was slightly high $(p<0.05)$ in exposed group as compared to control.
\end{abstract}

Keywords: Traffic policemen, lead pollution, traffic police, bilirubin, lactate dehydrogenase

\section{Introduction}

The common sources of lead are; lead-containing paint, water, leaded pipes from public water supply, Asian herbal remedies, lead-glazed ceramics, and lead shot game $\left[{ }^{29}\right]$. Whereas the most hazardous man-made source of lead is exhaust from motor vehicles using gasoline that contains alkyl lead added as an anti-knocking agent ${ }^{[39]}$. Gasoline combustion globally contributes an estimated $60 \%$ of total lead emissions ${ }^{[33]}$. Recorded mean concentration of lead in air is $80-4000 \mathrm{mg} / \mathrm{m}^{3}{ }^{[31]}$. Lead is largely emitted as fine particles by petrol combustion in inorganic state causing lead pollution of air and human beings. The major biochemical effect of lead is its interference with heme synthesis, which leads to hematological damage ${ }^{[32]}$. Lead may be deposited in the red blood corpuscles, soft tissues of children mainly in the kidney region, but the greater concerning matter is that 70 to $90 \%$ of this lead is deposited in bones. This is the most hazardous because the half-life of lead in the bones is 28 years, whereas lead in the blood and kidneys remains only up to two to four weeks ${ }^{[15]}$.

It is estimated that nearly half a million of children in the United States have blood lead levels high enough to cause irreversible damage to their health, lead paint being the major source of lead toxicity in children [29]. Typically, lead-intoxicated patients present with neurological complaints and neurobehavioral disorders. However, toxic levels of lead do not only affect the nervous system but also hematopoiesis and renal function ${ }^{[5,2]}$. Lead-induced liver damage is an uncommon finding and has anecdotally been reported ${ }^{[3]}$. The resulting histopathological changes have rarely been described in humans. However, descriptive animal studies reported that lead is a persistent metal and commonly present in our living environment. Even at low doses of developmental stages, lead exposure resulted in embryonic toxicity, behavioral alteration in adult been reported ${ }^{[26]}$, learning/memory deficit ${ }^{[8]}$. Consistently, Gargouri et al. ${ }^{[13]}$ studied the effect of lead acetate exposure in drinking water on mothers during gestation, from the 5th day of gestation to day 14 postpartum, revealing that caused lead deposition was found in the brain and cerebellum of newborns as well as cerebellum tissue damages and significant decrease in weight and protein content of these tissues. Oxidative stress and changes in antioxidant enzyme activities in brain tissues were also recorded ${ }^{[13]}$. Moreover, lead induced deficits in learning and memory through over activation of hippocampal serine/threonine protein phosphatases PP1 and PP2A ${ }^{[30]}$. In addition, lead acetate disturbed biochemical and hematological indices and induced nephrotoxicity and hepatoxicity through profound elevation of reactive oxygen species (ROS) production and oxidative stress, leading to increased lipid peroxidation level and depletion of intracellular reduced glutathione (GSH) level in 
kidney and liver ${ }^{[16,37,19]}$. Consistently, lead acetate has been found to induce biochemical and histological abnormalities in blood, kidney, liver and brain tissues ${ }^{[27]}$. Karita et al. ${ }^{[18]}$ reported a significant positive correlation between blood lead and total cholesterol and LDL levels. Prolonged exposure to lead insidiously affects the different organs and systems in the body resulting in hematopoietic, cardiovascular, hepatic, renal and neurological dysfunctions with biochemical changes in the body. Lead exposure is negatively correlated with hemoglobin and RBC count ${ }^{[18,35]}$. The kidneys are particularly susceptible to toxic effects of lead and may result in nephropathy, proximal tubular damage, glomerular sclerosis, interstitial fibrosis and lowered glomerular filtration rate ${ }^{[4,20]}$. Effects on cardiovascular system including hypertension, coronary heart disease, stroke, and peripheral arterial disease were also reported ${ }^{[22,24]}$. Many researchers reported the lead associated liver injury in occupational workers with raised alanine aminotransferase, alkaline phosphatase and lactate dehydrogenase (LDH) activity and the formation of bilirubin in serum can be increased due to an abnormally high peripheral breakdown of haemoglobin ${ }^{[38]}$. Faloppi et al. ${ }^{[12]}$ reported that LDH is a glycolytic key enzyme in the conversion of pyruvate to lactate under anaerobic conditions, and up-regulation of LDH may ensure both an efficient anaerobic/glycolytic metabolism and a reduced dependence on oxygen under hypoxic conditions in tumour cells.

Therefore, the objective of this study is to investigate the effect of lead poisoning on each of blood bilirubin and lactate dehydrogenase among exposed workers.

\section{Materials and methods}

Study area and sample size

This study was conducted in different cities of Sudan (Abohamad ,Marwy, Portsudan, kassalla ,Wadmadany ,Kostey, Gabalmarah, Alobed, Aldalang and Khartoum state). The samples size is 150 subjects (100 exposed taken from both petrol station workers and traffic policemen and 50 unexposed (control samples).

Study design:

A case - control study was conducted. Data was collected with the aid of writing a questionnaire.

\section{Sample collection:}

A total of 150 blood samples were collected from petrol stations and traffic policemen. Four ml of venous blood was taken from each exposed and control groups, then kept in clean heparanized container and stored in a refrigerator bending analyses. A questionnaire was designed to collect information, namely: address, age, sex, weight, smoking habit, duration of work, hour's day working and symptoms (Fatigue, headache, convulsion, numbsion, hypertension and GIT disorder).

\section{Lead extraction}

Lead was extracted from blood used NIOSH method, where two $\mathrm{ml}$ of blood was taken, then one ml of distill water was added, half $\mathrm{ml}$ of ammonium pyrrolidine dithiocarbonate and half $\mathrm{ml}$ of triton was added, $0.75 \mathrm{ml}$ of methyl isobutyl ketene was added. The mixture was then rotated in centrifuge; the top layer which contains lead was observed ${ }^{[25]}$.

\section{Lead concentration determination}

Lead concentration was estimated by an atomic absorption spectrometer.

\section{The biochemical measurements}

\section{Determination of Serum Total Bilirubin}

The total bilirubin was measured by Jendrassik and Grof method ${ }^{[7]}$. Bilirubin in the serum react with diazotided sulfanilic acid in the presence of DMSO formed azobilirbin. There are two bilirubin fractions in the serum, bilirubin-glucuronide and free bilirubin. The terms total bilirubin equivalents of the two bilirubin fractions.

\section{Determination of conjugated bilirubin concentration}

The conjugated bilirubin was measured by Jendrassik and Grof, method adopted by Cheesbrough ${ }^{[7]}$. Direct bilirubin is measured as the total bilirubin method but in absence of the caffeine- benzoate catalyst and at acid $\mathrm{pH}$. Under these conditions only the conjugated bilirubin will react.

Unconjugated bilirubin $(\mathrm{mg} / \mathrm{dl})=$ Total bilirubin concentration- Conjugated bilirubin

Determination of serum $\mathbf{L D H}$

Serum LDH activity was determination according to the method described by (Spanish Society of Clinical Chemistry1989).

\section{Statistical analysis}

T.test was applied for analysis of data, used statistical package for social science (SPSS). 


\section{Results and discussion}

A total of 150 blood samples were analyzed to investigate the lead content in the study groups. The analyzed samples revealed that lead was detected in all the investigated blood samples with different concentration levels, as given in figure (1). In Khartoum City, the concentration levels of mean blood lead in exposed group was nearly reached $45 \mu \mathrm{g} / \mathrm{dl}$ (the maximum permissible level that adopted by WHO for blood lead in adults is $40 \mu \mathrm{g} / \mathrm{dl}$ ), seconded by Wadmadany and Portsudan which both of them were above $35 \mu \mathrm{g} / \mathrm{dl}$ ). Alobed was almost reached $35 \mu \mathrm{g} / \mathrm{dl}$. Whereas exposed group in Abohamad, Marwy, Kosty and Kassala Towns were all found have mean blood lead levels above $30 \mu \mathrm{g} / \mathrm{dl}$, the result obtained for the mean blood Lead levels (about $20 \mu \mathrm{g} / \mathrm{dl}$ ) for exposed group belonging to Aldalang. The blood sample collected from Gabalmarah showed less concentration of leads (below $20 \mu \mathrm{g} / \mathrm{dl}$ ), as shown in figure (1). These differences may be due to differences of air lead pollution among exposed group. Khartoum is the most highly populated city and, therefore, the traffic policemen and fuel petrol workers have the highest blood lead levels. This could be attributed to lead emissions from motor vehicles. In unexposed group (control), the highest mean blood levels were found in Khartoum City (above $20 \mu \mathrm{g} / \mathrm{dl}$ ), while in both of Aldalang and Gabalmarah Towns were found to be less than $10 \mu \mathrm{g} / \mathrm{dl}$. The rest of control samples found to be have mean blood lead levels less than $15 \mu \mathrm{g} / \mathrm{dl}$.

In general, the obtained results clearly indicated that the blood samples collected from the Sudanese cities contained less concentration of blood lead when compared with the study that investigated lead content in blood samples of shopkeepers from different locations of Khyber Pukhtunkhwa, Pakistan, which found that blood lead levels were ranged from 227.5 to $381.1 \mu \mathrm{g} / \mathrm{dl}^{[36]}$. Another study conducted in traffic police constable of Karachi, Pakistan, found that the mean lead level was $47.8 \mu \mathrm{g} / \mathrm{dl}$ and attributed this variation to that shopkeeper in Khyber Pukhtunkhwa performed more duties in their shops range from 12 to 14 hrs every day. Another similar study was conducted in traffic controllers of Alexandria, Egypt, road intersections were reported high blood lead levels $(68 \pm 13 \mu \mathrm{g} / \mathrm{dl})$ and attributed this to that the Alexandria is the most highly populated city and the traffic police that control traffic lights at road manually and therefore, the high blood lead levels could be resulted to lead emissions from motor vehicles ${ }^{[36]}$.

On contrast, the effect of environmental lead pollution and high blood lead level has not always yielded convincing positive results. Many studies have failed to detect increased blood lead levels among traffic police, even when the subjects were tested with a sophisticated electro-thermal atomic absorption spectrometer ${ }^{[28]}$.

In our own opinion, the safety limit that was set for the maximum blood lead levels is not restrict and still controversial issue, Manser, et al. ${ }^{[21]}$, reported that the upper limits for blood lead levels has been often quoted as $40 \mu \mathrm{g} / \mathrm{dl}$ for adults and $30 \mu \mathrm{g} / \mathrm{dl}$ for children, while $25 \mu \mathrm{g} / \mathrm{dl}$ blood lead regarded as elevated in U.S.A as adopted by $\mathrm{CDC}^{[6]}$, and the European Committee decided on a mean acceptable value of $20 \mu \mathrm{g} / \mathrm{dl}{ }^{[9]}$. Therefore, severe actions should be made in order to minimize the use of fuel that contains lead, new restrict legislations and standard managements for lead intoxication also should be made by the Sudanese Government as are being practiced by the developed world. As shown in figure (2), the percentage of smokers in exposed group was higher (above 60\%) than that in unexposed control group (above 20\%). All variables showed positive correlation with air lead pollution, headache and fatigue seemed to be symptoms of blood lead poisoning, above $70 \%$ of exposed group suffer from headache while almost $70 \%$ of them suffer from fatigue. Only about $10 \%$ of exposed group suffer from convulsion while none of control group suffer from this variable. Similar percentage (above 40\%) was noticed in both exposed and unexposed groups regarding hypertension. Remarkable percentage (near 49\%) of gitdisorder was noticed in exposed group while in unexposed control group the percentage of gitdisorder was found to be about $21 \%$. It has been reported by Gotschi et al. ${ }^{[14]}$ that there are enough epidemiological studies demonstrated that vehicular pollution can cause increased morbidity and mortality, and some human health adverse effects may result from short-term exposure, while others are related to long-term exposure. Noteworthy to mention that Gotschi et al. ${ }^{[14]}$ stated that there are many different adverse health effects caused by air lead pollution, but the majority of previous studies, devoted to traffic policemen, have largely focused only on three specific outcomes; respiratory morbidity, cytogenic effect and carcinogenic effect.

Table (1) and table (2) showed the relationship between blood lead levels in both exposed and control groups and their work duration (year and hours/day, respectively). The increase in blood lead levels in the exposed group was exponentially correlated with the work duration. The differences of high blood lead concentrations due to long work duration were found to be significant $(\mathrm{P}<0.001)$. Agha et al. ${ }^{[1]}$ reported that there was no significant difference found in mean blood lead values at various age groups or work duration in the study conducted in traffic police constables in Islamabad, Pakistan, while the levels were found to be significantly $(\mathrm{p}<0.0001)$ high at all age groups in traffic constables of Karachi as compared to Islamabad. 


\section{Biochemical parameters:}

Comparison between LDH concentration in petrol station workers and traffic policemen and control samples in different cities in Sudan is shown in table (3), A student t test showed high significant $(\mathrm{P}<0.001)$ increase in LDH concentration in petrol station workers and traffic policemen (exposed group) compared to control. The obtained results of this study were further substantiated by previous studies that were conducted by Mikhail, et al. ${ }^{[23,17,10]}$.

Comparison between blood total bilirubin, direct bilirubin and in direct bilirubin concentrations in exposed and control sample in different cities in Sudan is shown in table (4). The blood total bilirubin, direct bilirubin and indirect bilirubin concentrations in exposed and control sample were slightly higher $(\mathrm{p}<0.05)$ in exposed group as compared to control. High concentration of lead has been shown to produce morphological changes and destruction of red cells when administered in vitro and in vivo ${ }^{[11]}$. Therefore, it appears that the higher bilirubin level could be a consequence of intravascular hemolysis.

\section{Conclusion And Recommendations}

The results of this study revealed a prevalence of elevated blood lead levels among many Sudanese traffic policemen and gasoline exposed professionals in the different cities of Sudan, and in Khartoum City was higher than the limit permitted by the World Health Organization. It was found an obvious increase in LDH, total bilirubin, direct bilirubin and in direct bilirubin blood lead level for Traffic- and Gasoline Exposed Professionals compared to control samples, Therefore, it is important to recognize that, in addition to further studies in this field, good health promotion and protection measures should be taken for Traffic- and Gasoline Exposed Professionals.

It is of paramount necessary to consider that the present study not included hazardous air particles come from the incomplete combustion e.g., nitrogen, sulfur oxide, carbon monoxide and other organic compounds, which may increase lead poisoning in the study groups.

It could be recommended that serious actions should be taken in order to minimize the use of fuel that contains lead, new restrict legislations and standard managements for lead intoxication should be made by the Sudanese Standard and Metrology Organization and stakeholders as are being practiced by the developed world.

\section{Acknowledgement}

The authors acknowledge the assistance of all those who contributed to this study.

\section{References}

[1]. Agha, F., Sadaruddin, A. and, Naz Khatoon. (2005). Effect of Environmental lead pollution on Blood Lead Levels in Traffic Police Constables in Islamabad, Pakistan J Pak Med Assoc, 55(10): 410-413.

[2]. Batuman V, Maesaka JK, Haddad B, Tepper E, Landy E, Wedeen RP (1981). The role of lead in gout nephropathy. N Engl J Med; 304: 520-523.

[3]. Beattie AD, Mullin PJ, Baxter RH, Moore MR (1979). Acute lead poisoning: an unusual cause of hepatitis. Scott Med J; 24: 318 321.

[4]. Bravo Y, Quiroz Y, Ferrebuz A, Vaziri N D, Rodriguez- Iturbe B (2007). Mycophenolate mofetil administration reduces renal inflammation, oxidative stress, and arterial pressure in rats with lead induced hypertension. Am. J. Renal. Physiol.; 293 (2): 616-23.

[5]. Cairney, S., Maruff, P., Burns, C.B., Currie, J., Currie, B.J. (2004). Neurological cerebellum of newborn rats. Food Chem Toxicol. (7):2303-10

[6]. CDC-Center for Disease Control and Prevention. (2002). Adult blood lead epidemiology and surveillance, United States, 19982001. MMWR Morb Mortal Wkly Rep; 51(11); 1-10.

[7]. Cheesbrough, M. (2006) District laboratory practice in tropical countries, part $1,2^{\text {rd }}$ addition, Cambridge University press, New York - USA, 350, 404

[8]. Chen, J., Chen, Y., Liu, W., Bai, C., Liu, X., Liu, K., Li, R., Zhu, J.H. and Huang, C. (2012): Developmental lead acetate exposure induces embryonic toxicity and memory deficit in adult zebrafish. Neurotoxicol Teratol. pii: S0892 0362(12)00149-3. (ahead of print). evaluation, and treatment. Altern Med Rev; 11: 2-22.

[9]. Di Farrante, E. (1979). Trace metals exposure and health effects. Proceedings of a research seminar held at the University of Surrey. Guildford, UK, 1978. Oxford, Pergamon Press, 1979.

[10]. Dioka, C.E., Orisakwe, O.E., Adeniyi, F.A., Meludu, S.C. (2004). Liver and renal function tests in artisans occupationally exposed to lead in mechanic village in Nnewi, Nigeria. : Int J Environ Res Public Health, 1(1):21-5.

[11]. Donaldson, W.E. (1993) Is lead toxicosis a reflection of altered fatty acid composition of membrane? Comp Biochem Physiol 1993; C104: 377-79.

[12]. Faloppi, L., Bianconi, M., Memeo, R., et al. (2016). Lactate Dehydrogenase in Hepatocellular Carcinoma: Something Old, Something New, BioMed Research International, Volume 2016 (2016), Article ID 7196280, 7 pages

[13]. Gargouri, M., Ghorbel-Koubaa, F., Bonenfant- Magné, M., Magné, C., Dauvergne, X., Ksouri, R., Krichen, Y., Abdelly, C. and El Feki, A.(2012). Spirulina or dandelion-enriched diet of mothers alleviates lead-induced damages in brain andcerebellum of newborn rats. Food Chem Toxicol. 50 (7):2303-10.

[14]. Gotschi, T., Heinrich, J., Sunyer, J., Kunzli, N. (2008). Long-term effects of ambient air pollution on lung function: A review. Epidemiology. 19:690-701.

[15]. Haque, M.M. (2005). Effects of calcium carbonate, potassium iodide and zinc sulfate in lead induced toxicities in mice. MS Thesis, Department of Pharmacology, BAU, Mymensingh.

[16]. Ibrahim, N.M, Eweis, E.A., el-Beltagi, H.S., And Abdel-Mobdy, Y.E. (2011), The effect of lead acetate toxicity on experimental male albino rat Biol Trace Elem Res. 144 (1-3):1120-32. 
[17]. Kapaki, E.N., Varelas, P.N., Syrigou, A.I., Spanaki, M.V., Andreadou, E., Kakami, A.E., Papageorgiou, C.T. (1998). Blood lead levels of traffic- and gasolineexposed professionals in the city of Athens. Arch Environ Health. Jul-Aug,53(4):287-91., 64, 65).

[18]. Karita, K., Yano, E., Dakeishi, M., Iwata, T., Murata, K. (2005). Benchmark dose of lead inducing anemia at the workplace. Risk Analysis.; 25 (4): 957-62.

[19]. Liu, C.M., Ma, J.Q. and Sun, Y.Z. (2012): Puerarin protects rat kidney from lead-induced apoptosis by modulating the PI3K/Akt/eNOS pathway. Toxicol Appl Pharmacol. 258(3):330-42.

[20]. Loghman-Adham, M. (1997). Renal effects of environmental and occupational lead exposure. Environ. Health Perspect. ; 105: 928 39.

[21]. Manser, W.W., Lalani, R., Haider, S., Khan, M.A. Trace element studies on Karachi Population. Part V. Blood lead levels in normal healthy adults and Grammar School children. J Pak Med Assoc 1990;40:150-4.

[22]. Menke, A., P. Muntner, V. Batuman, E. K. Silbergeld, and E. Guallar. (2006). Blood lead below $0.48 \mathrm{mu} \mathrm{mol/L} \mathrm{(10} \mathrm{mu} \mathrm{g/dL)} \mathrm{and}$ mortality among US adults. Circulation 114:1388-1394.

[23]. Mikhail, T.H., El-Sawaf, H.A., Ibrahim, K.M., Awadallah, R., El-Dessoukey, E.A. (1980). Evaluation of the effect of lead exposure on the liver in Egyptian lead tank welders. Z Ernahrungswiss, 19(1):50-6.

[24]. Navas-Acien, A, Guallar, E., Silbergeld, E.K, Rothenberg, S.J. (2007). Lead exposure and cardiovascular disease-a systematic review. Environ. Health Perspect.; 15: 472-82.

[25]. NIOSH (National Institute for Occupational Safety and Health) (1978), "criteria for a recommended standard occupational exposure to Inorganic lead -Revised Criteria' Cincinnati, DHEW (NIOSH) publication No. 78, pp 158.

[26]. Ochiai, K., Jin, K., Goryo, M., Tsuzuki, T., Itakura, C. Pathomorphologic (1993). Findings of lead poisoning in white-fronted geese (Anser albifrons). Vet Pathol; 30: 522-528.

[27]. Ozsoy, S.Y., Ozsoy, B., Ozyildiz, Z. and Aytekin, I. (2011): Protective effect of L- carnitine on experimental lead toxicity in rats: a clinical, histopathological and immunohistochemical study. Biotech. Histochem. 86 (6): 436-43.

[28]. Patil, R.R., Chetlapally, S. and Bbagavandas, M. (2014). Global review of studies on traffic police with special focus on environmental health effects. International Journal of Occupational Medicine and Environmental Health, 27(4): 523 - 535.

[29]. Patrick, L. (2006). Lead Toxicity, a Review of the Literature. Part I: Exposure, Evaluation, and Treatment Alternative Medicine Review u Volume 11.

[30]. Rahman, A., Khan, K.M., Al-Khaledi, G., Khan, I. and Al-Shemary, T. (2012): Over activation of hippocampal serine/threonine protein phosphatases PP1 and PP2A is involved in leadinduced deficits in learning and memory in young rats. Neurotoxicology. 33(3):370-83.

[31]. Schwartz, J. and Levine, R. (1991). The risk of lead toxicity in home with lead point hazard. Environmental Research 10: 1-7.

[32]. Seema, T., Tripathi, I.P. and Tiwari, H.I. (2014). Blood Lead Level-A Review. International Journal of Scientific Engineering and Technology, 3(4): 330-333.

[33]. Settle, D.M. and Patterson, C.C. (1980). Lead in albacore: guide to lead pollution in Americans. Science 14; 207(4436): 1167-76.

[34]. Spanish Society of Clinical Chemistry, Scientific Committee, Commission on Enzymes (1989). Methods recommended for the routine determination of the catalytic concentration in blood serum lactate dehydrogenase human .Quim Clin;8:57-61.

[35]. Stoleski, S., Karadzinska-Bislimovska, J., Stikova, E., Risteska- Kuc, S., Mijakoski, D., Minov, J. (2008). Adverse effects in workers exposed to inorganic lead. Arch. Hig. Rada. Toksikol.; 59 (1): 19-29

[36]. Ur Rehman, H., Farhan, Rehman A., Khattak, B., Abdul Khaliq, Shams, S. and Atlas, A. (2015). Estimation of Lead (Pb) in the Blood of Road Shopkeeper of KPK, Pakistan, World Applied Sciences Journal 33 (8): 1380-1382.

[37]. Wang, L., Wang, H., Li, J., Chen, D. and Liu, Z. (2011). Simultaneous effects of lead and cadmium on primary cultures of rat proximal tubular cells: interaction of apoptosis and oxidative stress. Arch Environ Contam Toxicol. 61(3):500-511.

[38]. Wickramasinghe, S.N, Wood, W.G. (2005). Advances in the understanding of the congenital dyserythropoietic anaemias. Br J Haematol, 131: 431-46

[39]. Yar Khan, S., Arshad, M., Arshad, N., Shazia Shafaat, S. and Hafiz Muhammad Tahir, H.M. (2016). A probable role of blood lead levels on some haematological parameters in traffic police, Lahore, Pakistan, Toxicology and Industrial Health, 32(5): 795-800.

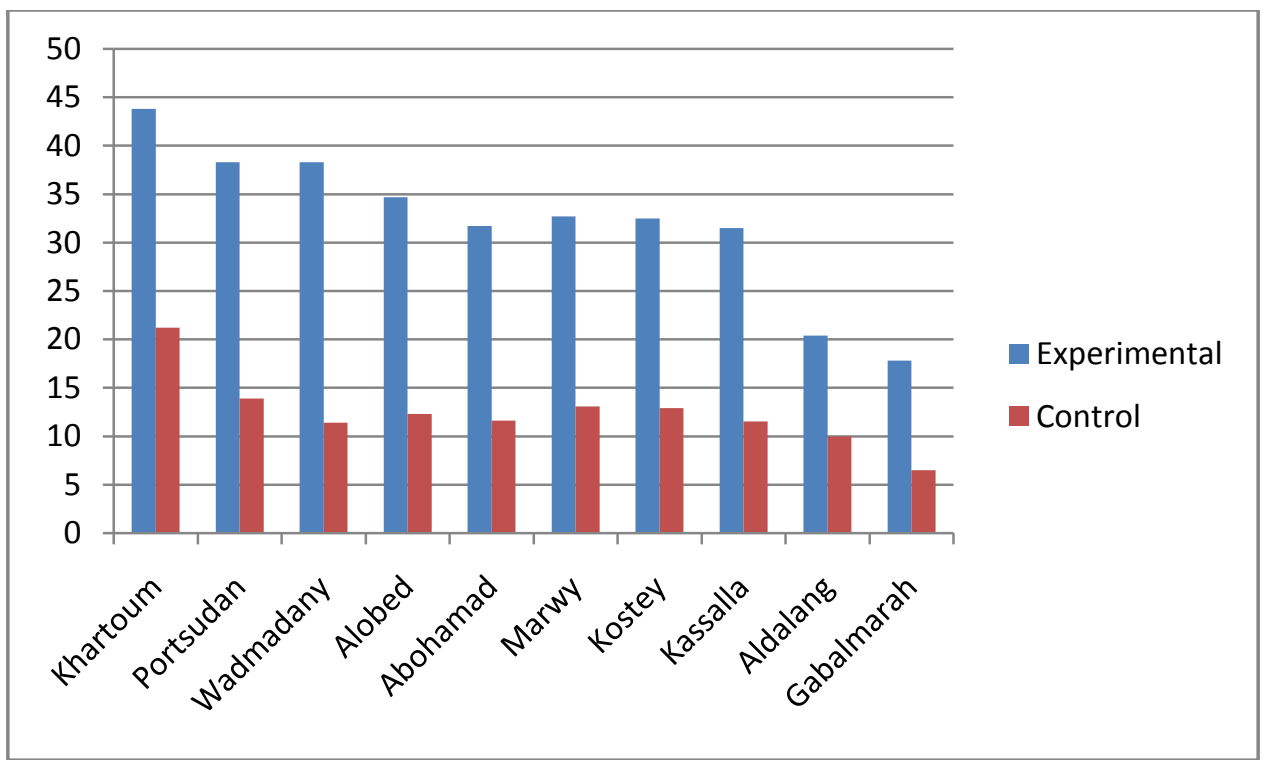

Fig (1): Shows descriptive data concerning the Blood lead levels from thetargeted professionals and the controls in different cities in Sudan. 


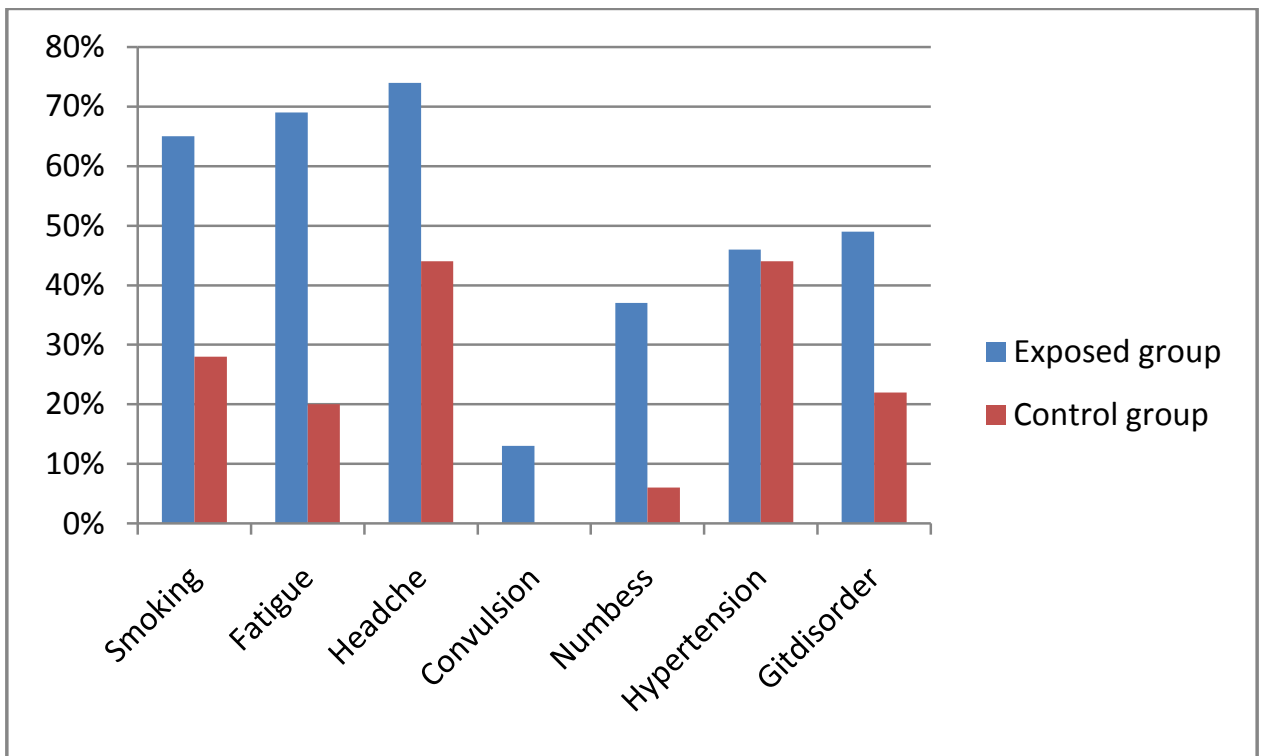

Fig (2) shows comparison between petrol station worker, traffic policemen and control samples using some variables in different cities in Sudan.

Table (1): shows the correlation between Work duration (year) and blood lead level for petrol station worker , traffic policemen Exposed in gasoline area for the study population in different cities in Sudan:-

\begin{tabular}{|l|l|l|l|}
\hline Work duration (Year) & Mean of lead concentration & Std. Error & Level of significant \\
\hline from 3 years to 9 & 21.06 & 0.778 & $* * *$ \\
\hline from 10 to 18 & 29.94 & 2.191 & $* * *$ \\
\hline$>\mathbf{1 9}$ & 45.82 & 2.761 & $* * *$ \\
\hline
\end{tabular}

$* * *$ significant at 0.001 level of probability

Table (2): shows the correlation between work periods (hours/day) and blood lead level for petrol station worker, traffic policemen exposed in gasoline area for the study population in different cities in Sudan:

\begin{tabular}{|l|l|l|l|}
\hline Work duration (hours/day) & Mean of lead concentration & Std. Error & Level of significant \\
\hline 6 to 9 & 25.82 & 1.836 & $* * *$ \\
\hline work 12 hour/day & 32.51 & 2.027 & $* * *$ \\
\hline work 13 to 16 hours /day & 39.84 & 3.742 & $* * *$ \\
\hline
\end{tabular}

Table (3): shows correlation between Blood enzyme lactate dehydrogenase (LDH) concentration for petrol station worker, traffic policemen exposed and control groups in different cities in Sudan

\begin{tabular}{|l|l|l|l|l|l|}
\hline $\begin{array}{l}\text { Parameters (Blood } \\
\text { enzymes) (U/L) }\end{array}$ & $\begin{array}{l}\text { Exposed } \\
\text { mean }\end{array}$ & $\begin{array}{l}\text { control } \\
\text { mean }\end{array}$ & d.f & S.E+ & $\begin{array}{l}\text { Level of } \\
\text { Significant }\end{array}$ \\
\hline LDH & 58.943 & 47.408 & 148 & 1.6159 & $* * *$ \\
\hline
\end{tabular}

$* * *$ significant at 0.001 level of probability.

Table (4): shows correlation between blood total bilirubin, direct bilirubin and in direct bilirubin concentration for petrol station worker, traffic policemen Exposed and control groups in different cities in Sudan.

\begin{tabular}{|l|l|l|l|l|l|}
\hline $\begin{array}{l}\text { Parameters } \\
\text { (mg/dl) }\end{array}$ & $\begin{array}{l}\text { Exposed } \\
\text { mean }\end{array}$ & control mean & d.f & S.E+ & $\begin{array}{l}\text { Level of } \\
\text { significant }\end{array}$ \\
\hline Total Bilirubin & 1.16 & 1.004 & 148 & 0.027 & $*$ \\
\hline D.Bilirubin & 0.252 & 0.234 & 148 & 0.002 & N.S \\
\hline In. Bilirubin & 0.908 & 0.772 & 148 & 0.025 & $*$ \\
\hline
\end{tabular}

*significant at 0.05 , N.S not significant. at level of probability 